\title{
Ab initio study of $\beta$-alanine conformers in the gas phase
}

\author{
Annia Galano*a ${ }^{a}$ J. Raúl Alvarez-Idaboy ${ }^{\mathrm{a}}$ \\ ${ }^{a}$ Instituto Mexicano del Petróleo, Eje Central Lázaro Cárdenas 152, 007730, México D. F., México \\ E-mail:agalano@imp.mx
}

\section{Dedicated to Professor Eusebio Juaristi on the occasion of his $55^{\text {th }}$ birthday}

(received 09 Dec 04; accepted 16 Feb 05; published on the web 19 Feb 05)

\begin{abstract}
Twelve conformers of non-ionized $\beta$-alanine have been investigated using high level ab-initio methods. Geometry optimizations and frequency calculations have been performed at MP2/6$311 \mathrm{G}(\mathrm{d}, \mathrm{p})$ and MP2/6-311++G(d,p) levels of calculation. Relative energies, rotational constants, harmonic vibrational frequencies and infrared intensities are reported. The relevance of using basis sets including diffuse functions has been supported. A factor of 0.9814 is proposed to scale the MP2/6-311++G(d,p) vibrational frequencies. The good agreement between the theoretical results and the available experimental values supports the reliability of the MP $2 / 6-311++G(d, p)$ level of theory for describing the conformational behavior of molecules with internal hydrogen bonds.
\end{abstract}

Keywords: $\beta$-Alanine, conformers, MP2, scaling factor, vibrational frequencies, diffused basis set

\section{Introduction}

Amino acids exist as zwitterions in solution and in the crystalline state, stabilized by electrostatic, polarization, and H-bonding interactions with their environment. ${ }^{1-4}$ In the gas phase, where these intermolecular interactions have no effect, they exist as non-ionized species. Error! Bookmark not defined.,Error! Bookmark not defined. The study of the conformational behavior of non-ionized amino acids is important for understanding the dynamics of the peptide and protein backbones.

$\beta$-Amino acids, although much less abundant than their $\alpha$ partners, are also present in peptides, and in free form they show interesting pharmacological effects. They can be cyclized to $\beta$-lactams which have potential biological activity. In this respect, several methods for the synthesis of racemic $\beta$-amino acids have been developed, ${ }^{5-7}$ and in the last few decades special attention has been paid to the preparation of enantiomerically pure compounds. Professor 
Juaristi, to whom this commemorative issue is dedicated, and co-workers have made significant contributions to this field of investigation. ${ }^{8-21}$

Although the conformational flexibility of free, non-ionized $\alpha$-amino acids is now very well established, both experimentally ${ }^{22}$ and theoretically, ${ }^{23}$ there is a lack of information on the $\beta$ conformers. Since the experimental investigation of gaseous amino acids is quite difficult, computational chemistry could become a very useful tool providing important information on such systems.

In the present work we have chosen $\beta$-alanine because it is the simplest of the $\beta$-amino acids, therefore this molecule is sufficiently small to allow high quality calculations. The conformational behaviour of $\beta$-alanine zwitterion has been recently established by NMR spectroscopy. ${ }^{24,25}$ It has also been investigated by post-Hartree-Fock and density functional methods (DFT) ${ }^{26}$ However, there are very few conformational studies on the non-ionized form of $\beta$-alanine. ${ }^{27-29}$ In reference Error! Bookmark not defined. it has been established that the Hartree-Fock method is not reliable enough for quantitative predictions of conformers' equilibrium, while the approaches including electron correlation (DFT, MP2 and MP4) perform remarkably well when using medium size basis sets including diffuse functions. The validity of the post Hartree-Fock methods for describing conformational behaviours has also been shown for the $\alpha$ amino acids.Error! Bookmark not defined. Accordingly, we have chosen the MP2/6$311 \mathrm{G}(\mathrm{d}, \mathrm{p})$ and MP2/6-311++G(d,p) levels of theory for the study of the non-ionized $\beta$-alanine conformers. The previous studies on this molecule ${ }^{\text {Error! Bookmark not defined.-Error! Bookmark not defined. }}$ were performed with no correlated methods and with non diffused basis sets.

\section{Computational Details}

All the calculations have been performed with the Gaussian $98^{30}$ package of programs. Relaxed scan calculations were carried out for all the torsions responsible for the non-rigidity of the molecule. They were performed trough the full $360^{\circ}$ space with steps of $10^{\circ}$, using the secondorder Møller-Plesset (MP2) method ${ }^{31,32}$ and the 6-311G(d,p) and 6-311++G(d,p) basis sets. The minima structures were identified and considered identical if their energies differed by less than $10^{-5}$ hartree and if the root-mean-square difference of their rotational frequencies differed by less than $30 \mathrm{MHz}$. Twelve unique conformations were then fully optimized and frequency calculations were carried out, all at MP2/6-311G(d,p) and MP2/6-311++G(d,p) levels of theory. They were verified to be minima by establishing that their matrices of second derivatives (hessians) were positive definite upon diagonalization. The hessians were all determined analytically. Relative energies were calculated at $0 \mathrm{~K}$ and $298 \mathrm{~K}$. Zero point corrections (ZPE) and thermal corrections (TCE) to energy were included. The MP2/6-311G(d,p) values were corrected by using the recommended scaling factors. The ZPE and TCE values computed at MP2/6-311++G(d,p) level have not been corrected, since, to our best knowledge, there are no scaling factors reported for that level of calculation. 


\section{Results and Discussion}

$\beta$-Alanine shows four large amplitude vibrations responsible for the non-rigidity of the molecule. They have been presented in Figure 1 as: $\boldsymbol{\varphi}_{1}$ (- $\mathrm{NH}_{2}$ torsion), $\boldsymbol{\varphi}_{2}$ (central C2-C5 torsion), $\boldsymbol{\varphi}_{3}$ ($\mathrm{COOH}$ torsion), and $\varphi_{4}$ (hydroxyl torsion). The $\varphi$ variables can be identified with dihedral angles as $\varphi_{1}=\mathrm{H} 12 \mathrm{~N} 7 \mathrm{C} 5 \mathrm{C} 2, \boldsymbol{\varphi}_{2}=\mathrm{N} 7 \mathrm{C} 5 \mathrm{C} 2 \mathrm{C} 4, \boldsymbol{\varphi}_{3}=\mathrm{O} 6 \mathrm{C} 4 \mathrm{C} 2 \mathrm{C} 5$, and $\boldsymbol{\varphi}_{4}=\mathrm{H} 11 \mathrm{O} 10 \mathrm{C} 4 \mathrm{C} 2$. The torsions corresponding to variations in $\varphi_{1}$ and $\varphi_{4}$ can be interpreted as the internal rotations of tops $-\mathrm{NH}_{2}$ and $-\mathrm{OH}$, with respect to a fixed frame. In contrast variations in $\boldsymbol{\varphi}_{2}$ and $\boldsymbol{\varphi}_{3}$ involve two tops of similar weights and consequently they can hardly be considered as separated movements.

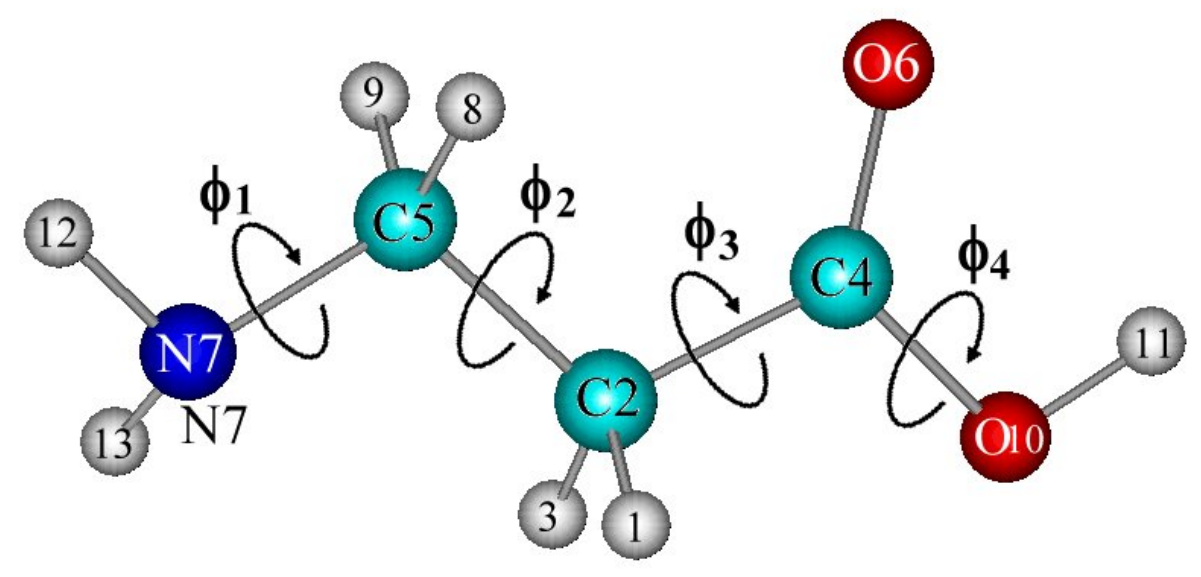

Figure 1. Atoms numbering and torsional coordinates.

Twelve different conformations were found for $\beta$-alanine by varying the torsional variables describing above (Figure 2). Their values of $\varphi_{1}, \varphi_{2}, \varphi_{3}$, and $\varphi_{4}$ are shown in Table I, as well as the energies relative to conformer $I$ at $0 \mathrm{~K}$ and at $298 \mathrm{~K}$. The data is reported at two different levels of calculation: MP2/6-311G(d,p) and MP2/6-311++G(d,p). In order to present more accurate values the Zero Point Energy correction (ZPE) and the thermal correction to energy (TCE), they have been improved by using the scaling factors recommended by Scott and Radom. $^{33}$ at MP2/6-311G(d,p) level of theory. The MP2/6-311++G(d,p) ZPE and TCE values have not been corrected, since, to our best knowledge, there are no scaling factors reported for that level of calculation. 
Table 1. MP2/6-311++G(d,p) molecular parameters defining $\beta$-alanine conformations, and energies $(\mathrm{kcal} / \mathrm{mol})$, relative to conformer $I$

\begin{tabular}{|c|c|c|c|c|c|c|c|c|}
\hline \multirow{2}{*}{ Conf. } & \multirow{2}{*}{$\varphi_{1}$} & \multirow{2}{*}{$\varphi_{2}$} & \multirow{2}{*}{$\varphi_{3}$} & \multirow{2}{*}{$\varphi_{4}$} & \multicolumn{2}{|c|}{$6-311 G(d, p)$} & \multicolumn{2}{|c|}{$6-311++G(d, p)$} \\
\hline & & & & & $\mathrm{E}(0 \mathrm{~K})$ & $\mathrm{E}(298 \mathrm{~K})$ & $\mathrm{E}(0 \mathrm{~K})$ & $\mathrm{E}(298 \mathrm{~K})$ \\
\hline 1 & 79.9 & 64.6 & 141.2 & 3.76 & 0.00 & 0.00 & 0.00 & 0.00 \\
\hline 2 & 166.1 & 64.4 & 6.15 & -179.4 & 0.24 & 0.53 & -0.41 & -0.11 \\
\hline 3 & -62.8 & 63.3 & 11.8 & -178.2 & 0.67 & 0.95 & 0.33 & 0.63 \\
\hline 4 & 66.4 & 53.9 & -122.9 & -178.3 & 1.70 & 1.99 & 0.79 & 1.09 \\
\hline 5 & 170.6 & -60.9 & -55.6 & -178.9 & 1.70 & 2.03 & 0.87 & 1.20 \\
\hline 6 & 175.1 & -175.4 & 12.6 & -177.9 & 1.87 & 2.31 & 1.08 & 1.54 \\
\hline 7 & -59.3 & 180.0 & -0.09 & 180.0 & 2.04 & 2.48 & 1.52 & 2.03 \\
\hline 8 & 166.2 & 57.7 & -149.4 & 177.7 & 2.11 & 2.43 & 1.22 & 1.55 \\
\hline 9 & 175.7 & 80.19 & 127.2 & 179.8 & 2.37 & 2.70 & 1.58 & 1.89 \\
\hline 10 & 173.9 & 177.8 & -118.5 & -179.5 & 2.67 & 3.10 & 1.61 & 2.04 \\
\hline 11 & 175.1 & -175.4 & 12.6 & -177.9 & 2.92 & 3.40 & 1.08 & 1.54 \\
\hline 12 & 172.5 & -176.2 & -1.985 & -1.920 & 7.37 & 7.88 & 6.31 & 6.88 \\
\hline
\end{tabular}



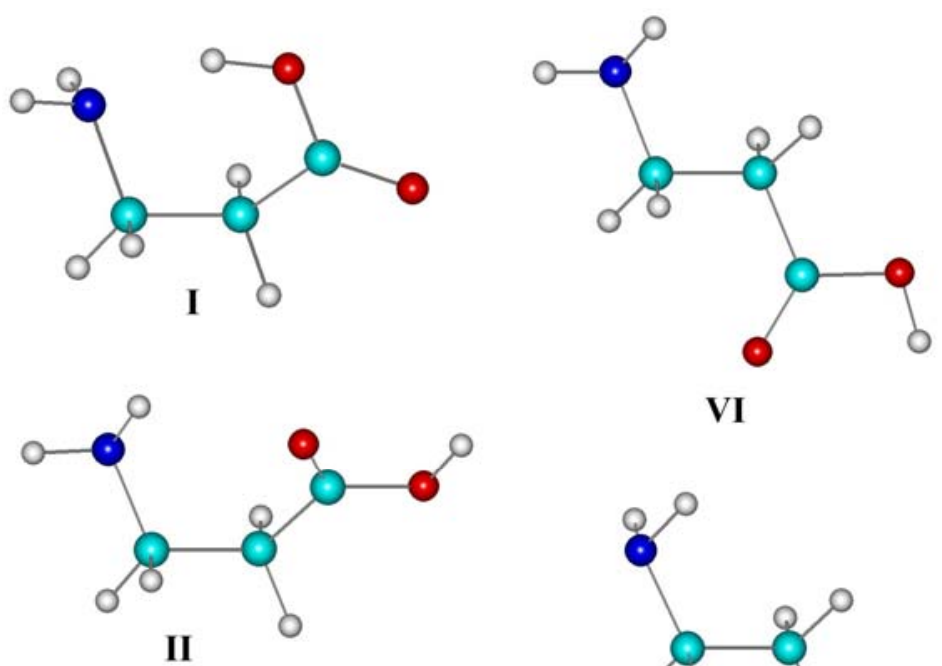

VI
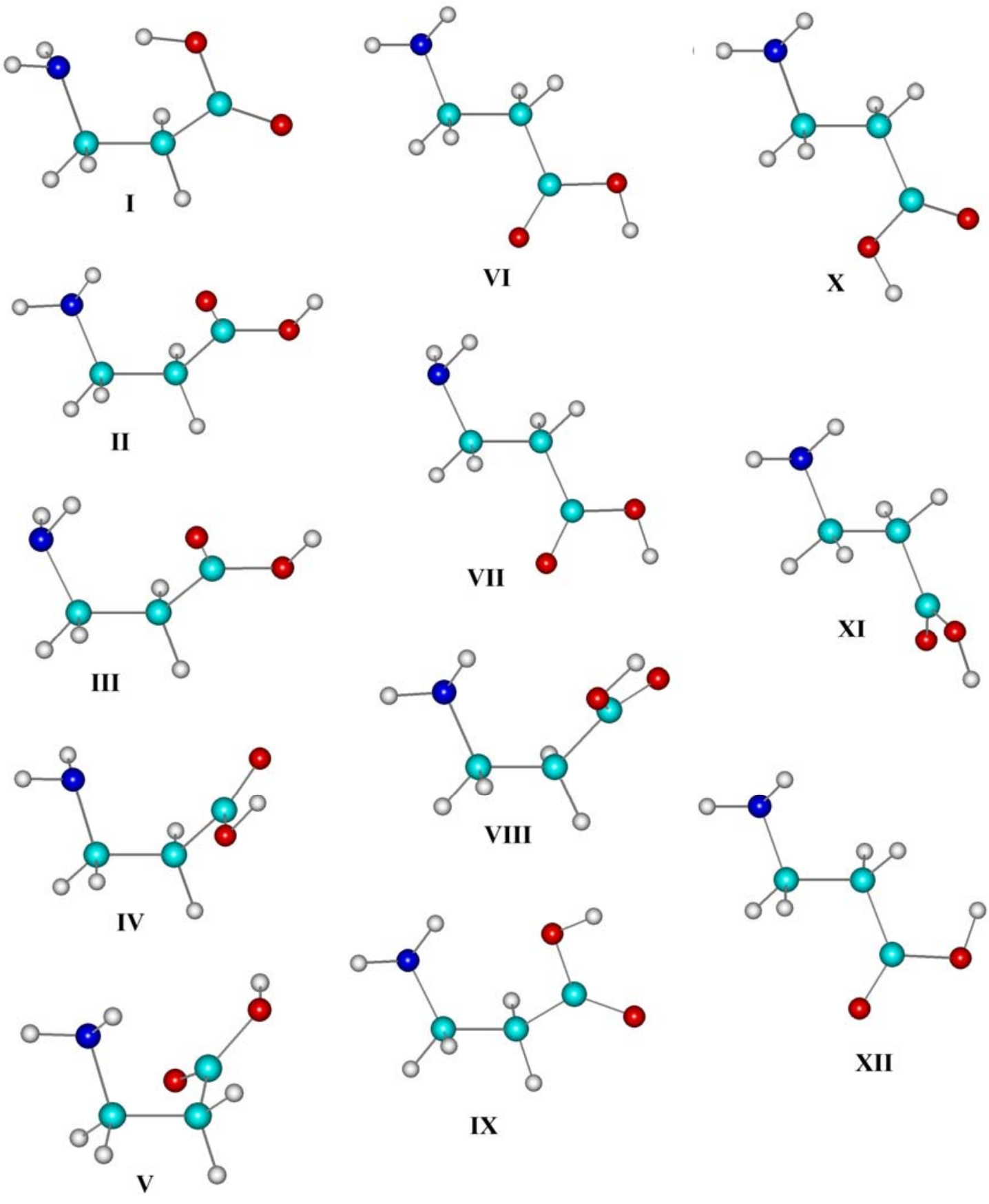

IX

Figure 2. Conformers of $\beta$-alanine corresponding to local energy minima on the MP2/6$311 \mathrm{G}(\mathrm{d}, \mathrm{p})$ potential energy surface.

The relative energy values in Table 1 show a discrepancy between the results obtained with the $6-311 \mathrm{G}(\mathrm{d}, \mathrm{p})$ and the $6-311++\mathrm{G}(\mathrm{d}, \mathrm{p})$ basis sets. The discrepancy could be caused by the overestimation of internal hydrogen bonds when the used basis set do not include diffuse functions, which was previously pointed out by Nielsen et al. ${ }^{\text {Error! Bookmark not defined. }}$ In order to 
clarify that, a more detailed analysis on the possible intra-molecular interactions in $\beta$-alanine conformers is needed. Bader topological analysis ${ }^{34}$ of the MP2/6-311G(d,p) wave functions, corresponding to all the studied conformers, were performed in order to identify and quantify all possible intra-molecular interactions (Table 2). All the hydrogen bond interactions lead to ring critical points in the corresponding conformers. The strongest internal hydrogen bond was found in conformer $I$, between H11 and N7. The interaction distance was found to be $d(7,11)=1.77 \AA$, which is the shortest distance among all the found interactions. The shortest distance and the largest value of electronic charge density $(\rho)$ and of the Laplacian of $\rho,\left(\nabla^{2} \rho\right)$ at the critical points, show that the N7-H11 interaction in conformer $I$ is the strongest one. This finding reinforces the hypothesis that non diffused basis set overestimate the effect of internal hydrogen bonds on the energy values. In our case this overestimation is found responsible for the prediction of conformer $I$ as the most stable at MP2/6-311G(d,p) level of theory. However, there is crucial to find another way to prove that the relative energies obtained at MP2/6-311++G(d,p) are the correct ones.

Table 2. Characterization of the intra-molecular interactions found in the $\beta$-alanine conformers

\begin{tabular}{cccccc}
\hline Conf. & $\begin{array}{c}\text { Critical } \\
\text { Points }\end{array}$ & $\begin{array}{c}\text { Atoms } \\
\text { involved }\end{array}$ & $\begin{array}{c}\text { Atomic } \\
\text { distance }\end{array}$ & $\rho$ & $\nabla^{2} \rho$ \\
\hline I & Bond & 7,11 & 1.769 & 0.049 & -0.028 \\
& Ring & $7,5,2,4,10,11$ & - & 0.018 & -0.026 \\
II & Bond & 6,13 & 2.366 & 0.012 & -0.011 \\
& Ring & $6,4,2,5,7,13$ & - & 0.011 & -0.013 \\
III & Bond & 6,12 & 2.404 & 0.012 & -0.011 \\
& Ring & $6,4,2,5,7,12$ & - & 0.011 & -0.013 \\
VIII & Bond & 10,13 & 2.522 & 0.009 & -0.009 \\
& Ring & $10,4,2,5,7,13$ & - & 0.009 & -0.010 \\
IX & Bond & 10,13 & 2.250 & 0.014 & -0.014 \\
& Ring & $10,4,2,5,7,13$ & - & 0.010 & -0.014 \\
\hline
\end{tabular}

Two conformers of $\beta$-alanine have been previously identified by McGlone and Godfrey ${ }^{\text {Error! }}$ Bookmark not defined. by using a Stark-modulated free-expansion jet spectrometer. The authors named them $\beta$-ala $(x)$ and $\beta$-ala $(y)$. Hereafter we are referring to them accordingly. Their observations led to identify $\beta$-ala(x) as the lowest energy conformation. Their spectroscopic derived parameters are reported in Table 3 and have been used as reference for comparing our results. Calculations on the trideutero analogues of all the studied conformers have also been performed. The data of the non-deuterated and deuterated parent species, as well as the associated changes in the rotational constants are reported in Table 3 . Since the changes in the rotational constants on deuteration are a function of the amino and hydroxyl hydrogen positions, they can be use to select which of the modeling conformers correspond to those identified in reference Error! Bookmark not defined.. From the agreement on the rotational constants and on their variation, 
the calculated conformers corresponding to those observed by McGlone and Godfrey are: conformer $I I=\beta$-ala(x) and conformer $I \beta$-ala(y). This validate the MP2/6-311++G(d,p) relative energies and reinforces the relevance of using basis set with diffuse functions, even if correlation methods are employed. Now, it seems reasonable to rely on the MP2/6-311++G(d,p) results and propose conformer $I I$ as the most stable one.

Table 3. MP2/6-311++G(d,p) rotational constants $(\mathrm{GHz})$

\begin{tabular}{|c|c|c|c|c|c|c|}
\hline Conf. & A & $\mathrm{B}$ & $\mathrm{C}$ & $\Delta(\mathrm{A})$ & $\Delta(\mathrm{B})$ & $\Delta(\mathrm{C})$ \\
\hline$\beta$-ala $(x)^{\mathrm{a}}$ & 7.268 & 2.335 & 1.987 & & & \\
\hline$d_{3}-\beta-a l a(x)^{a}$ & 7.003 & 2.145 & 1.835 & 0.264 & 0.190 & 0.151 \\
\hline$\beta$-ala $(y)^{\mathrm{a}}$ & 7.177 & 2.500 & 1.982 & & & \\
\hline $\mathrm{d}_{3}-\beta-\mathrm{ala}(\mathrm{y})^{\mathrm{a}}$ & 6.805 & 2.330 & 1.866 & 0.372 & 0.169 & 0.116 \\
\hline I & 7.172 & 2.513 & 1.993 & & & \\
\hline$d_{3}-I$ & 6.804 & 2.342 & 1.876 & 0.368 & 0.171 & 0.117 \\
\hline II & 7.159 & 2.363 & 2.011 & & & \\
\hline $\mathrm{d}_{3}-\mathrm{II}$ & 6.889 & 2.168 & 1.857 & 0.270 & 0.195 & 0.154 \\
\hline III & 6.982 & 2.313 & 2.005 & & & \\
\hline $\mathrm{d}_{3}$-III & 6.584 & 2.147 & 1.887 & 0.398 & 0.166 & 0.119 \\
\hline IV & 5.742 & 2.486 & 2.354 & & & \\
\hline $\mathrm{d}_{3}-\mathrm{IV}$ & 5.373 & 2.293 & 2.182 & 0.369 & 0.193 & 0.172 \\
\hline V & 5.825 & 2.435 & 2.296 & & & \\
\hline $\mathrm{d}_{3}-\mathrm{V}$ & 5.499 & 2.237 & 2.114 & 0.326 & 0.198 & 0.182 \\
\hline VI & 9.195 & 1.858 & 1.585 & & & \\
\hline$d_{3^{-}} V I$ & 8.933 & 1.678 & 1.449 & 0.263 & 0.179 & 0.136 \\
\hline VII & 9.184 & 1.834 & 1.571 & & & \\
\hline $\mathrm{d}_{3}$-VII & 8.933 & 1.678 & 1.449 & 0.252 & 0.156 & 0.122 \\
\hline VIII & 6.321 & 2.433 & 2.200 & & & \\
\hline $\mathrm{d}_{3}-$ VIII & 5.884 & 2.279 & 2.047 & 0.437 & 0.154 & 0.153 \\
\hline IX & 7.168 & 2.405 & 1.938 & & & \\
\hline$d_{3}-I X$ & 6.664 & 2.253 & 1.806 & 0.503 & 0.151 & 0.132 \\
\hline X & 8.465 & 1.895 & 1.668 & & & \\
\hline $\mathrm{d}_{3}-\mathrm{X}$ & 8.032 & 1.731 & 1.527 & 0.433 & 0.164 & 0.141 \\
\hline XI & 9.195 & 1.858 & 1.585 & & & \\
\hline $\mathrm{d}_{3}-\mathrm{XI}$ & 8.932 & 1.678 & 1.449 & 0.263 & 0.179 & 0.136 \\
\hline XII & 9.045 & 1.859 & 1.580 & & & \\
\hline $\mathrm{d}_{3}$-XII & 8.405 & 1.706 & 1.456 & 0.641 & 0.153 & 0.124 \\
\hline
\end{tabular}

${ }^{\text {a }}$ Reference Error! Bookmark not defined..

As it has been previously established, the ab-initio vibrational frequencies $(\omega)$ are typically larger than the fundamentals $(v)$ observed experimentally. ${ }^{35}$ A major source of this disagreement 
is the neglect of anharmonicity effects in the theoretical treatment. Other causes are the incomplete incorporation of electron correlation and the use of finite basis set. However, the overestimation of ab-initio vibrational frequencies is relatively uniform, and consequently frequency scaling factors are often applied. Scott and Radom ${ }^{\text {Error! Bookmark not defined. }}$ recommend a scaling factor of 0.9496 for the MP2/6-311G(d,p) vibrational frequencies. However, there is no scaling factor recommended for frequencies computed at MP2/6-311++G(d,p). Analyzing the MP2/6-311G(d,p) scaled frequencies together with the MP2/6-311++G(d,p) harmonic frequencies of all the studied conformers, a scaling factor of 0.9814 has been used in the present work to correct the latter ones. The information contained in the MP2/6-311++G(d,p) theoretical vibrational frequencies and infrared intensities reported in Table IV, for the six most stable conformers of $\beta$-alanine, could help on the interpretation of experimental investigation of the gas-phase vibrational spectrum of this amino acid.

The results summarized in Table 4 show that there are some normal modes which do not change significantly from one conformer to another. The band corresponding to $\omega_{26}(-\mathrm{C}=\mathrm{O}$ stretching) appears as the most intense one in all conformers but $I$, and its frequency changes very little among them, from 1777 (II, III) to 1805 (XII) $\mathrm{cm}^{-1}$. However, some normal modes with high IR intensities shift considerably. For example the modes involving the $-\mathrm{OH}$ group. In conformer $I$ the mode corresponding to the $-\mathrm{OH}$ stretching $\left(\omega_{31}\right)$ shifts towards lower frequencies in about $450 \mathrm{~cm}^{-1}$, been the highest intensity vibration of this conformer, while the peak of the $-\mathrm{OH}$ torsion $\left(\omega_{13}\right)$ shifts towards higher frequencies in about $350 \mathrm{~cm}^{-1}$. These changes can be explained by the strong intra-molecular hydrogen bond in conformer $I$, involving the hydrogen atom in the $-\mathrm{OH}$ group. High intensity normal modes whose frequency does not change from one conformer to another should serve as indicators of the presence of $\beta$-alanine, while characteristic shifts should help identification of $\beta$-alanine conformers. 
Table 4. MP2/6-311++G(d,p) vibrational frequencies $\left(\mathrm{cm}^{-1}\right)$ and infrared intensities $(\mathrm{km} / \mathrm{mol})$ corresponding to the six most stable conformers of $\beta$-alanine

\begin{tabular}{|c|c|c|c|c|c|c|c|c|c|c|c|c|}
\hline & \multicolumn{2}{|c|}{ I } & \multicolumn{2}{|c|}{ II } & \multicolumn{2}{|c|}{ III } & \multicolumn{2}{|c|}{ IV } & \multicolumn{2}{|c|}{$\mathrm{V}$} & \multicolumn{2}{|c|}{ VI } \\
\hline & $\omega$ & $\mathrm{I}$ & $\omega$ & $\mathrm{I}$ & $\omega$ & $\mathrm{I}$ & $\omega$ & $\mathrm{I}$ & $\omega$ & $\mathrm{I}$ & $\omega$ & I \\
\hline 1 & 86 & 0.5 & 51 & 1.7 & 44 & 0.2 & 73 & 1.3 & 47 & 2.6 & 44 & 3.0 \\
\hline 2 & 203 & 6.0 & 149 & 1.7 & 144 & 1.7 & 121 & 2.7 & 124 & 1.0 & 107 & 2.3 \\
\hline 3 & 273 & 8.1 & 240 & 12.0 & 229 & 3.1 & 225 & 12.8 & 218 & 18.1 & 177 & 3.7 \\
\hline 4 & 329 & 5.8 & 292 & 48.0 & 329 & 46.5 & 276 & 20.8 & 267 & 20.3 & 249 & 45.1 \\
\hline 5 & 402 & 13.1 & 363 & 7.0 & 353 & 11.7 & 396 & 1.8 & 397 & 1.3 & 373 & 2.5 \\
\hline 6 & 486 & 9.6 & 485 & 42.8 & 491 & 17.8 & 460 & 2.2 & 448 & 8.2 & 445 & 16.7 \\
\hline 7 & 568 & 3.1 & 509 & 28.8 & 512 & 40.5 & 552 & 50.2 & 550 & 44.7 & 509 & 41.7 \\
\hline 8 & 690 & 7.5 & 616 & 34.2 & 613 & 20.6 & 590 & 92.8 & 616 & 83.0 & 624 & 80.9 \\
\hline 9 & 812 & 12.5 & 633 & 74.9 & 634 & 80.1 & 691 & 35.6 & 704 & 46.9 & 637 & 41.1 \\
\hline 10 & 869 & 51.4 & 805 & 5.8 & 791 & 28.8 & 805 & 60.1 & 806 & 64.4 & 793 & 20.7 \\
\hline 11 & 915 & 23.4 & 867 & 71.0 & 854 & 173.6 & 846 & 65.2 & 850 & 62.9 & 861 & 94.1 \\
\hline 12 & 952 & 30.6 & 896 & 49.2 & 878 & 30.4 & 906 & 11.6 & 907 & 8.1 & 896 & 17.4 \\
\hline 13 & 982 & 84.0 & 950 & 6.0 & 934 & 3.4 & 973 & 4.6 & 973 & 6.6 & 993 & 15.6 \\
\hline 14 & 1016 & 13.5 & 1061 & 20.9 & 1030 & 22.5 & 1012 & 37.6 & 1023 & 8.8 & 1066 & 39.9 \\
\hline 15 & 1083 & 6.0 & 1114 & 41.3 & 1114 & 58.8 & 1089 & 54.7 & 1094 & 42.5 & 1102 & 66.7 \\
\hline 16 & 1137 & 11.0 & 1126 & 176.0 & 1123 & 148.6 & 1116 & 52.2 & 1116 & 94.6 & 1131 & 140.2 \\
\hline 17 & 1232 & 89.2 & 1196 & 101.7 & 1185 & 86.9 & 1207 & 139.6 & 1191 & 167.6 & 1171 & 71.6 \\
\hline 18 & 1281 & 15.6 & 1222 & 3.5 & 1242 & 20.7 & 1252 & 9.9 & 1256 & 12.8 & 1250 & 14.9 \\
\hline 19 & 1302 & 5.8 & 1295 & 7.1 & 1292 & 5.3 & 1302 & 9.4 & 1291 & 1.2 & 1289 & 2.2 \\
\hline 20 & 1358 & 7.5 & 1341 & 4.8 & 1372 & 33.5 & 1325 & 25.0 & 1322 & 11.6 & 1322 & 1.9 \\
\hline 21 & 1407 & 8.9 & 1398 & 66.4 & 1385 & 5.4 & 1376 & 34.4 & 1398 & 71.9 & 1376 & 58.7 \\
\hline 22 & 1449 & 13.4 & 1420 & 33.8 & 1403 & 54.2 & 1415 & 12.2 & 1409 & 12.1 & 1434 & 61.9 \\
\hline 23 & 1470 & 233.2 & 1435 & 17.8 & 1439 & 17.4 & 1459 & 14.9 & 1464 & 14.2 & 1450 & 9.2 \\
\hline 24 & 1501 & 5.1 & 1491 & 3.0 & 1474 & 5.7 & 1504 & 2.0 & 1501 & 4.8 & 1504 & 1.0 \\
\hline 25 & 1615 & 31.2 & 1622 & 61.9 & 1629 & 26.3 & 1624 & 33.8 & 1623 & 31.9 & 1629 & 33.8 \\
\hline 26 & 1788 & 374.9 & 1777 & 237.5 & 1777 & 249.7 & 1789 & 292.9 & 1787 & 268.2 & 1781 & 262.6 \\
\hline 27 & 3013 & 45.2 & 2991 & 51.4 & 3020 & 7.9 & 2979 & 70.5 & 2983 & 67.4 & 2989 & 46.4 \\
\hline 28 & 3020 & 5.7 & 3033 & 7.7 & 3040 & 30.3 & 3042 & 9.0 & 3042 & 9.5 & 3034 & 6.6 \\
\hline 29 & 3080 & 16.7 & 3074 & 23.3 & 3074 & 6.1 & 3085 & 5.8 & 3084 & 5.4 & 3078 & 0.7 \\
\hline 30 & 3110 & 5.4 & 3094 & 5.1 & 3099 & 17.5 & 3109 & 14.5 & 3107 & 14.2 & 3096 & 17.7 \\
\hline 31 & 3290 & 792.7 & 3482 & 2.4 & 3479 & 1.3 & 3473 & 0.5 & 3475 & 0.5 & 3473 & 0.3 \\
\hline 32 & 3469 & 0.8 & 3575 & 10.1 & 3579 & 7.9 & 3571 & 5.0 & 3573 & 5.1 & 3568 & 3.6 \\
\hline 33 & 3562 & 12.4 & 3731 & 75.4 & 3728 & 74.6 & 3737 & 76.9 & 3726 & 70.4 & 3731 & 74.1 \\
\hline
\end{tabular}




\section{Conclusions}

Twelve different conformers of gaseous $\beta$-alanine were identified. The minima structures have been considered identical if their energies differ by less than $10^{-5}$ hartree and if the root-meansquare difference of their rotational frequencies differ by less than $30 \mathrm{MHz}$.

Geometry optimizations and frequency calculations have been performed at MP2/6$311 \mathrm{G}(\mathrm{d}, \mathrm{p})$ and MP2/6-311++G(d,p) levels of calculation. The relevance of using basis sets including diffuse functions to correctly predict the relative energies of the conformers has been supported.

Relative energies, rotational constants, harmonic vibrational frequencies and infrared intensities are reported. A factor of 0.9814 is proposed to scale MP2/6-311++G(d,p) vibrational frequencies.

The good agreement between the theoretical results and the available experimental values supports the reliability of the MP2/6-311++G(d,p) level of theory for describing the conformational behavior of molecules with internal hydrogen bonds.

\section{Acknowledgements}

The authors gratefully acknowledge the financial support from the Instituto Mexicano del Petróleo (IMP) through program D00179. We also thank the IMP Computing Center for supercomputer time on SGI Origin 2000.

\section{References}

1. Levy, H. A.; Corey, R. B. J. Am. Chem. Soc. 1941, 63, 2095.

2. Donohue, J. J. Am. Chem. Soc. 1950, 72, 949.

3. Junk, G.; Sevec, H. J. Am. Chem. Soc. 1963, 63, 2095.

4. Almlöf, J.; Kuick, A.; Thomas, J. O. J. Chem. Phys 1973, 85, 839.

5. Seebach, D.; Schiess, M.; Betachart, C. Helv. Chin. Acta 1984, 67, 1593.

6. Kim, S.; Oh, C. H.; KO, J. S.; Ahn, K. H.; Kim, Y. J. J. Org. Chem. 1985, 50, 927.

7. Wieber, G. M.; Hegedus, L. S.; Alkermark, B.; Michalson, E. T. J. Org. Chem. 1989, 54, 4649.

8. Juaristi, E.; Quintana, D.; Lamatsch, B.; Seebach, D. J. Org. Chem. 1991, 56, 2553.

9. Juaristi, E.; Escalante, J.; Lamatsch, B.; Seebach, D. J. Org. Chem. 1992, 57, 2396.

10. Murer, P.; Rheiner, B.; Juaristi, E.; Seebach, D. Heterocycles 1994, 39, 319.

11. Juaristi, E.; Quintana, D.; Escalante, J. Aldrichimica Acta 1994, $27,3$.

12. Juaristi, E.; Seebach, D. In Enantioselective Synthesis of [ß]-Amino Acids, Juaristi, E. Ed.; Wiley-VCH: New York, 1997; Ch. 13, pp $261-277$. 
13. Juaristi, E.; Balderas, M.; Ramirez-Quiros, Y. Tetrahedron-Asymetry 1998, 9, 3881.

14. Juaristi, E.; López-Ruíz, H. Curr. Med. Chem. 1999, 6, 519.

15. Juaristi, E.; Balderas, M.; Lopez-Ruiz, H.; Jimenez-Perez, V. M.; Kaiser-Carril, M. L.; Ramirez-Quiros, Y. Tetrahedron-Asymetry 1999, 10, 3493.

16. Gutierrez-Garcia, V. M.; Lopez-Ruiz, H.; Reyes-Rangel, G.; Juaristi, E. Tetrahedron 2001, $57,6487$.

17. Gutierrez-Garcia, V. M.; Reyes-Rangel, G.; Munoz-Muniz, O.; Juaristi, E. J. Braz. Chem. Soc. 2001, 12, 652.

18. Gutierrez-Garcia, V. M.; Reyes-Rangel, G.; Munoz-Muniz, O.; Juaristi, E. Helv. Chim. Acta 2002, 85, 4189.

19. Munoz-Muniz, O.; Juaristi, E. Tetrahedron 2003, 59, 4223.

20. Iglesias-Arteaga, M. A.; Castellanos, E.; Juaristi, E. Tetrahedron-Asymetry 2003, 14, 577.

21. Castellanos, E.; Reyes-Rangel, G.; Juaristi, E. Helv. Chim. Acta 2004, 87, 1016.

22. See for example: (a) Grenie, Y.; Lassegues, J. C.; Lagrange, C. G. J. Chem. Phys. 1970, 53, 2980. (b) Grenie, Y.; Lagrange, C. G. J. Mol. Spectrosc. 1972, 41, 240. (c) Debies, T. P.; Rabalais, J. W. J. Electron Spectrosc. Relat. Phenom. 1974, 3, 315. (d) Klasinc, L. J. Electron Spectrosc. Relat. Phenom. 1976, 8, 161. (e) Brown, R. D.; Godfrey, P. D.; Storey, J. W. V.; Bassez, M. P. J. Chem. Soc. Chem. Commun. 1978, 547. (f) Suenram, R. D.; Lovas, F. J. J. Mol. Spectrosc. 1978, 72, 372. (g) Suenram, R. D.; Lovas, F. J. J. Am. Chem. Soc. 1980, 102, 7180. (h) Iijima, K.; Tanaka, K.; Onuma, S. J. Mol. Struct. 1991, 246, 257. (i) Iijima, K.; Beagley, B. J. Mol. Struct. 1991, 248, 133. (j) Godfrey, P. D.; Firth, S.; Hatherley, L. D.; Brown, R. D.; Pierlot, A. P. J. Am. Chem. Soc. 1993, 115, 9687. (k) Reva, I. D.; Stepanian, S. G.; Plokhotnichenko, A. M.; Radchenko, E. D.; Sheina, G. G.; Blagoi, Y. P. J. Mol. Struct. 1994, 318, 1. (1) Reva, I. D.; Plokhotnichenko, A. M.; Stepanian, S. G.; Ivanov, A. Y.; Radchenko, E. D.; Sheina, G. G.; Blagoi, Y. P. Chem. Phys. Lett. 1995, 232, 141. (m) Godfrey, P. D.; Brown, R. D. J. Am. Chem. Soc. 1995, 117, 2019.

23. See for example: (a) Vishveshwara, S.; Pople, J. A. J. Am. Chem. Soc. 1977, 99, 2422 (b) Clementi, E.; Cavallone, F.; Scordamaglia, R. J. Am. Chem. Soc. 1977, 99, 5531. (c) Sellers, H. L.; Schäfer, L. J. Am. Chem. Soc. 1978, 100, 7728 (d) Wright, L. R.; Borkman, R. F. J. Am. Chem. Soc. 1980, 102, 6207. (e) Schäfer, L.; Sellers, H. L.; Lovas, F. J.; Suenram, R. D. J. Am. Chem. Soc. 1980, 102, 6566. (f) Palla, P.; Petrongolo, C.; Tomasi, J. J. Phys. Chem. 1980, 84, 435. (g) Sapse, A. M.; Mallah-Levy, L.; Daniels, S. B.; Erickson, B. W. J. Am. Chem. Soc. 1987, 109, 3526. (h) Destro, R.; Marsh, R. E.; Bianchi, R. J. Phys. Chem. 1988, 92, 966. (i) Schäfer, L.; Kulp-Newton, S. Q.; Siam, K.; Klimkowski, V. J.; van Alsenoy, C. J. Mol. Struct. 1990, 209, 373. (j) Jensen, J. H.; Gordon, M. S. J. Am. Chem. Soc. 1991, 113, 7917. (k) Frey, R. F.; Coffin, J.; Newton, S. Q.; Ramek, M.; Cheng, V. K. W.; Momany, F. A.; Schäfer, L. J. Am. Chem. Soc. 1992, 114, 5369. (1) Jensen, J. H.; Baldridge, K. K.; Gordon, M. S. J. Phys. Chem. 1992, 96, 8340. (m) Hu, C.-H.; Shen, M.; Schaefer, H. F., III. J. Am. Chem. Soc. 1993, 115, 2923. (n) Császár, A. G. J. Mol. Struct. 1995, 346, 141. (o) 
Gronert, S.; O’Hair, R. A. J. J. Am. Chem. Soc. 1995, 117, 2071. (p) Császár, A. G. J. Chem. Phys. 1996, 100, 3541.

24. Gregoire. F.; Wei, S. H.; Streed, E. W.; Brameld, K. A.; Fort, D.; Hanely, L. J.; Goddard, W. A.; Roberts, J. D. J. Am. Chem. Soc. 1998, 120, 7537.

25. Abraham, R. J.; Loftus, P.; Thomas, A. W. Tetrahedron 1977, 33, 1227.

26. Nielsen, P. A.; Norrby, P. O.; Liljefors, T.; Rega, N.; Barone, V. J. Am. Chem. Soc. 2000, $122,3151$.

27. Ramek, M. J. Mol. Struct. (Theochem) 1990, 208, 301.

28. Ramek, M.; Flock, M.; Kelterer, A.-M.; Cheng, V. K. W. J. Mol. Struct. (Theochem) 1992 , 276, 61 .

29. McGlone, S. J.; Godfrey, P. D. J. Am. Chem. Soc. 1995, 117, 1043.

30. Gaussian 98 Revision A.3, Frisch, M. J.; Trucks, G. W.; Schlegel, H. B.; Scuseria, G. E.; Robb, M. A.; Cheeseman, J. R.; Zakrzewski, V. G.; Montgomery Jr., J. A.; Stratmann, R. E.; Burant J. C.; Dapprich, S.; Millam, J. M.; Daniels, A. D.; Kudin, K. N.; Strain, M. C.; Farkas, O.; Tomasi, J.; Barone, V.; Cossi, M.; Cammi, R.; Mennucci, B.; Pomelli, C.; Adamo, C.; Clifford, S.; Ochterski, J.; Petersson, G. A.; Ayala, P. Y.; Cui, Q.; Morokuma, K.; Malick, D. K.; Rabuck, A. D.; Raghavachari, K.; Foresman, J. B.; Cioslowski, J.; Ortiz, J. V.; Stefanov, B. B.; Liu, G.; Liashenko, A.; Piskorz, P.; Komaromi, I.; Gomperts, R.; Martin, R. L.; Fox, D. J.; Keith, T.; Al-Laham, M. A.; Peng, C. Y.; Nanayakkara, A.; Gonzalez, C.; Challacombe, M.; Gill, P. M. W.; Johnson, B.; Chen, W.; Wong, M. W.; Andres, J. L.; Gonzalez, C.; Head-Gordon, M.; Replogle, E. S.; Pople, J. A. Gaussian, Inc., Pittsburgh PA., 1998.

31. Møller, C.; Plesset, M. S. Phys. Rev. 1934, 46, 618.

32. Krishnan, R.; Frish, M. J.; Pople, J. A. J. Chem. Phys. 1980, 72, 4244.

33. Scott, A. P.; Radom, L. J. Phys. Chem. 1996, 100, 16502.

34. Bader, R. F. W. Atoms in Molecules - A Quantum Theory, Oxford University Press: Oxford, 1990.

35. Hehre, W. J.; Radom, L.; Schleyer, P. v. R.; Pople, J. A. Ab Initio Molecular Orbital Theory, Wiley: New York, 1986. 